\title{
Queuing Analysis on Multiple Vacation Policies and Reneging
}

\author{
P. Suthersan, S. MaragathaSundari
}

\begin{abstract}
We study a non markovian queue which renders service to the customers. After the completion of service the server ought to go for the compulsory vacation stage by stage in succession. We consider one of the customer's behaviors reneging to occur when the server's vacation is extended. Using Supplementary variable technique the system performance measures is derived.
\end{abstract}

Keywords: Stages of service, Optional extended vacation, Reneging, Extended Vacation

\section{INTRODUCTION}

Cluster section with escape lines are the theme of concentrate for [3]. "Reference [1] Has considered retrial queuing structures with server breakdown". "Reference [7] has inquired about the thoughts of restricted agreeableness and optional sorts of fix in a Non Markovian line". "Reference [14] have considered the execution extents of the mass data line with $\mathrm{N}$ sorts of additional optional organizations and organization impedance". "Reference [6] has made an examination of a group passage of organization in two stages with reinforcement server in the midst of general escape time and general fix time". "Reference [2] have considered a group section line of organization in two stages with Bernoulli plan escape sought after by a widely inclusive escape and advantage impedance". "Reference [4] made a covering approach in Mobile adhoc systems". "Reference [5] examined the Bernoulli plan study and association interference on non markovian covering model". "Reference [9] attempt to unify several classes of related batch arrival queuing systems". "Reference [10] studied M/G/1 queuing system with bulk arrival". "Reference [11] considered an M/G/1 queue with three stages of service with different general service time distributions". "Reference [12] studied a single server queue, two phases of service with optional second phase service following a general service time distribution". "Reference [13] studied a batch arrival queuing system in which the server may face occasional random breakdowns".

Revised Manuscript Received on December 15, 2019.

* Correspondence Author

P. Suthersan, Department of Mathematics, Kalasalingam Academy of Research and Education, Krishnankovil, Tamilnadu. Email: sudersan.p@klu.ac.in

S. MaragathaSundari*, Department of Mathematics, Kalasalingam Academy of Research and Education, Krishnankovil, Tamilnadu. Email: maragatham01@gmail.com

\section{MATHEMATICAL DESCRIPTION OF THE QUEUEING MODEL}

The arithmetical interpretation of the Queuing framework has the capacity to be described by the resulting hypothesis:

Customer's arrival follows Poisson procedure. There is one server giving administration. The organization time seeks after general (arbitrary) course with first basic dispersion

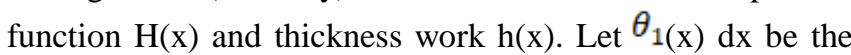
prohibitive chance of organization finish of the principle period of organization in the midst of the interval $(x, x+d x)$, given that the snuck past time is $\mathrm{x}$, so that

$$
\theta_{1}(\mathrm{x})=\frac{h(x)}{1-H(x)} \quad h(x)=\theta_{1}(\mathrm{x}) e^{-\int_{0}^{s} \theta_{1}(\mathrm{x}) d x} .
$$

For First stage of compulsory vacation,

$$
\theta_{2}(\mathrm{x})=\frac{u(x)}{1-U(x)} \quad, u(x)=\theta_{1}(\mathrm{x}) e^{-\int_{0}^{t} \theta_{1}(\mathrm{x}) d x} .
$$

For Second Stage of compulsory vacation,

$$
\theta_{3}(\mathrm{x})=\frac{m(x)}{1-M(x)} \quad, m(x)=\theta_{3}(\mathrm{x}) e^{-\int_{0}^{t} \theta_{3}(\mathrm{x}) d x} .
$$

For $\quad$ Optional $\quad$ Extended
$\theta_{4}(\mathrm{x})=\frac{f(x)}{1-F(x)} \quad, f(x)=\theta_{4}(\mathrm{x}) e^{-\int_{0}^{t} \theta_{4}(\mathrm{x}) d x}$

Vacation,

Reneging occur during extended vacation with probability $r$

\section{PROBABILITY GENERATING FUNCTION}

$$
\begin{aligned}
& K_{n}(x, z)=\sum_{n=1}^{\infty} z^{n} K_{n}(x) ; K_{n}(z)=\sum_{n=1}^{\infty} z^{n} K_{n},|z| \leq 1 \\
& C_{n}^{(1)}(x, z)=\sum_{n=1}^{\infty} z^{n} C_{n}^{(1)}(x) ; C_{n}^{(1)}(z)=\sum_{n=1}^{\infty} z^{n} C_{n}^{(1)}, \\
& C_{n}^{(2)}(x, z)=\sum_{n=1}^{\infty} z^{n} C_{n}^{(2)}(x) ; C_{n}^{(2)}(z)=\sum_{n=1}^{\infty} z^{n} C_{n}^{(2)}, \\
& E_{n}(x, z)=\sum_{n=1}^{\infty} z^{n} E_{n}(x) ; E_{n}(z)=\sum_{n=1}^{\infty} z^{n} E_{n} .
\end{aligned}
$$

\section{STEADY STATE CONDITIONS OVERSEEING} THE FRAMEWORK

$$
\begin{aligned}
& \frac{\partial}{\partial x} K_{n}(x)+\frac{\partial}{\partial x}\left(\lambda^{P}+\theta_{1}(\mathrm{x})\right) K_{n}(x)=\lambda^{P} K_{n-1}(x) . \\
& \frac{\partial}{\partial x} K_{0}(x)+\frac{\partial}{\partial x}\left(\lambda^{P}+\theta_{1}(\mathrm{x})\right) K_{0}(x)=0 .(2) \\
& \frac{\partial}{\partial x} C_{n}^{(1)}(x)+\frac{\partial}{\partial x}\left(\lambda^{P}+\theta_{2}(\mathrm{x})\right) C_{n}^{(1)}(x)=\lambda^{P} C_{n-1}^{(1)}(x) . \\
& \frac{\partial}{\partial x} C_{0}^{(1)}(x)+\frac{\partial}{\partial x}\left(\lambda^{P}+\theta_{2}(\mathrm{x})\right) C_{0}^{(1)}(x)=0 . \\
& \frac{\partial}{\partial x} C_{n}^{(2)}(x)+\frac{\partial}{\partial x}\left(\lambda^{P}+\theta_{3}(\mathrm{x})\right) C_{n}^{(2)}(x)=\lambda^{P} C_{n-1}^{(2)}(x) . \\
& \frac{\partial}{\partial x} C_{0}^{(2)}(x)+\frac{\partial}{\partial x}\left(\lambda^{P}+\theta_{3}(\mathrm{x})\right) C_{0}^{(2)}(x)=0 .
\end{aligned}
$$

$\frac{\partial}{\partial x} E_{n}(x)+\frac{\partial}{\partial x}\left(\lambda^{P}+\theta_{4}(\mathrm{x})+\xi\right) E_{n}(x)=\lambda^{P} E_{n-1}(x)+$ $\xi E_{n+1}(x)$

$x>0, n \geq 1$. 
$\frac{\partial}{\partial x} E_{0}(x)+\frac{\partial}{\partial x}\left(\lambda^{P}+\theta_{4}(\mathrm{x})+\xi\right) E_{0}(x)=\xi E_{1}(x)$.

$\lambda S=\int_{0}^{\infty} C_{0}^{(2)}(x) \theta_{3}(\mathrm{x}) \mathrm{dx}+\int_{0}^{\infty} E_{0}(x) \theta_{4}(\mathrm{x}) \mathrm{dx}+$ $\int_{0}^{\infty} K_{0}(x) \theta_{1}(\mathrm{x}) \mathrm{dx}$

\section{BOUNDARY CONDITIONS}

The above set of equations is to be solved under the following boundary conditions at $x=0$ and for $x \geq 1$

$$
K_{n}(0)=
$$

$\int_{0}^{\infty} K_{n+1}(x) \theta_{1}(\mathrm{x}) d x+(1-r) \int_{0}^{\infty} C_{n+1}^{(2)}(x) \theta_{3}(\mathrm{x}) \mathrm{dx}+$ $\int_{0}^{\infty} E_{n+1}(x) \theta_{4}(\mathrm{x}) \mathrm{dx}+\lambda S$

$C_{n}^{(1)}(0)=\int_{0}^{\infty} K_{n}(x) \theta_{1}(\mathrm{x}) d x$.

$C_{n}^{(2)}(0)=\int_{0}^{\infty} C_{n}^{(1)}(x) \theta_{2}(\mathrm{x}) d x$.

$E_{n}(0)=r \int_{0}^{\infty} C_{n}^{(2)}(x) \theta_{3}(\mathrm{x}) d x$

Multiply (1) by $z^{n}$ and sum over ${ }^{n}$ from 1 to ${ }^{\infty}$,

Adding to (2), we

$\frac{\partial}{\partial x} K_{n}(x, z)+\left(\lambda^{P}+\theta_{1}(\mathrm{x})-\lambda^{P} z\right) K_{n}(x, z)=0$.

$\frac{\partial}{\partial x} C_{n}^{(1)}(x, z)+\left(\lambda^{P}+\theta_{2}(\mathrm{x})-\lambda^{P} z\right) C_{n}^{(1)}(x, z)=0$.

$\frac{\partial}{\partial x} C_{n}^{(2)}(x, z)+\left(\lambda^{P}+\theta_{3}(\mathrm{x})-\lambda^{P} z\right) C_{n}^{(2)}(x, z)=0$.

$\frac{\partial}{\partial x} E_{n}(x, z)+\left(\lambda^{P}+\theta_{4}(\mathrm{x})-\lambda^{P} z+\xi-\frac{\xi}{z}\right) K_{n}(x, z)=0$.

$$
\begin{aligned}
& \int_{0}^{\infty} C_{n}^{(2)}(x, z) \theta_{2}(\mathrm{x}) d x=K_{n}(0, z) J_{1}^{*}(A) J_{2}^{*}(A) J_{3}^{*}(A) \\
& E_{n}(\mathrm{z})=E_{n}(0, z)\left[\frac{1-J_{4}^{*}(D)}{D}\right] \\
& \text { Where } D=\lambda^{P}-\lambda^{P} z+\xi-\frac{\xi}{z} \\
& \quad=r K_{n}(0, z) J_{1}^{*}(A) J_{2}^{*}(A) J_{3}^{*}(A)\left[\frac{1-J_{4}^{*}(D)}{D}\right] . \\
& \int_{0}^{\infty} E_{n}(x, z) \theta_{4}(\mathrm{x}) d x=r K_{n}(0, z) J_{1}^{*}(A) J_{2}^{*}(A) J_{3}^{*}(A) J_{4}^{*}(D) .
\end{aligned}
$$

Substituting (24),(28),(30) in (18), we get $K_{n}(0, z)=\frac{\left(\lambda^{P} Z-\lambda^{P}\right) s}{\left[z-J_{1}^{*}(A)-\left(J_{1}^{*}(A) J_{2}^{*}(A) J_{3}^{*}(A)\right)\left(1+r J_{4}^{*}(D)\right)\right]}$.

Hence (23), (25) ,(27) ,(29) becomes,

$K_{n}(z)=\frac{s\left(\lambda^{P} Z-\lambda^{P}\right)\left[\frac{1-J_{1}^{*}(A)}{A}\right]}{\left.\left.\left.\left[z-J_{1}^{*}(A)-\left(J_{1}^{*}(A)\right]_{2}^{*}(A)\right]_{3}^{*}(A)\right)(1+r]_{4}^{*}(D)\right)\right]}$.

$C_{n}^{(1)}(z)=\frac{S J_{1}^{*}(A)\left(\lambda^{P} Z-\lambda^{P}\right)\left[\frac{1-J_{2}^{*}(A)}{A}\right]}{\left.\left.\left.\left[z-J_{1}^{*}(A)-\left(J_{1}^{*}(A)\right]_{2}^{*}(A)\right]_{2}^{*}(A)\right)(1+r]_{4}^{*}(D)\right)\right]}$.

$C_{n}^{(2)}(\mathrm{z})=\frac{S J_{1}^{*}(A) J_{2}^{*}(A)\left(\lambda^{P} Z-\lambda^{P}\right)\left[\frac{\left[-J_{3}^{*}(A)\right.}{A}\right]}{\left[z-J_{1}^{*}(A)-\left(J_{1}^{*}(A) J_{2}^{*}(A) J_{3}^{*}(A)\right)\left(1+r J_{4}^{*}(D)\right)\right]}$.

$E_{n}(\mathrm{z})=\frac{r S J_{1}^{*}(A) J_{2}^{*}(A) J_{3}^{*}(A)\left(\lambda^{P} Z-\lambda^{P}\right)\left[\frac{1-J_{4}^{*}(D)}{D}\right]}{\left[z-J_{1}^{*}(A)-\left(J_{1}^{*}(A) J_{2}^{*}(A) J_{3}^{*}(A)\right)\left(1+r J_{4}^{*}(D)\right)\right]}$

Next applying the procedure of supplementary variable for the boundary conditions, we have

$z K_{n}(0, z)=$

$\int_{0}^{\infty} K_{n}(x, z) \theta_{1}(\mathrm{x}) d x+(1-r) \int_{0}^{\infty} C_{n}^{(2)}(x, z) \theta_{3}(\mathrm{x}) d x+$

$\int_{0}^{\infty} E_{n}(x, z) \theta_{4}(\mathrm{x}) d x-\lambda^{P} S+\lambda^{P} z S$

$C_{n}^{(1)}(0, z)=\int_{0}^{\infty} K_{n}(x, z) \theta_{1}(\mathrm{x}) d x$.

$C_{n}^{(2)}(0, z)=\int_{0}^{\infty} C_{n}^{(1)}(x, z) \theta_{2}(\mathrm{x}) d x$.

$E_{n}(0, z)=r \int_{0}^{\infty} C_{n}^{(2)}(x, z) \theta_{3}(\mathrm{x}) d x$.

Integrating (14) from 0 to $\infty$, we get $K_{n}(x, z)=K_{n}(0, z) e^{-\left(\lambda^{P}-\lambda^{P} z\right) x-\int_{0}^{x} \theta_{1}(\mathrm{t}) d t}$.

Again integrating the above by parts, we get $K_{n}(z)=K_{n}(0, z)\left[\frac{1-J_{1}^{*}(A)}{A}\right]$.

where $\quad A=\lambda^{P}-\lambda^{P} z$

$I_{1}^{*}(A)=\int_{0}^{\infty} e^{-\left(\lambda^{P}-\lambda^{P} z\right) x} d J_{1}(x)$ is the Laplace Stieltje's transform of service time. Again multiplying (22) by $\theta_{1}(\mathrm{x})$ on both the sides and integrating over $x$, we get $\int_{0}^{\infty} K_{n}(x, z) \theta_{1}(\mathrm{x}) d x=K_{n}(0, z) J_{1}^{*}(A)$.

Similarly for vacation process, we have $C_{n}^{(1)}(z)=C_{n}^{(1)}(0, z)\left[\frac{1-J_{2}^{*}(A)}{A}\right]$

$$
=K_{n}(0, z) J_{1}^{*}(A)\left[\frac{1-J_{2}^{*}(A)}{A}\right] \text {. }
$$

$\int_{0}^{\infty} C_{n}^{(1)}(x, z) \theta_{2}(\mathrm{x}) d x=K_{n}(0, z) J_{1}^{*}(A) J_{2}^{*}(A)$

\section{LIKELIHOOD CREATING CAPACITY OF THE LINE ESTIMATE}

To discover the likelihood making point of confinement of the line check paying little personality to the condition of the structure, we let $Y_{q}(z)$ be the p.g.f of the line length

$F(z)=$

$K_{n}(z)+C_{n}^{(1)}(z)+C_{n}^{(2)}(z)+E_{n}(z)$

$\left\{\begin{array}{c}\left(U_{1}^{*}(A)-1\right)+J_{1}^{*}(A)\left(U_{2}^{*}(A)-1\right)+J_{1}^{*}(A) J_{2}^{*}(A)\left(U_{3}^{*}(A)-1\right)+ \\ J_{1}^{*}(A) J_{2}^{*}(A) J_{3}^{*}(A)\left[\frac{1-J_{4}^{*}(D)}{D}\right]\end{array}\right\}$

\section{NORMALIZATION CONDITION}

$F(1)+S=1$ Gives the idle time $\mathrm{S}$ and the Utilization factor. Idle time

$S=\frac{D^{\prime}(1)}{D^{\prime}(1)+N^{\prime}(1)}$

Utilization factor, $\rho=1-S$.

$F(1)=\lim _{z \rightarrow 1} F(z)=\frac{0}{0}$, indeterminate form.

Hence applying L'Hopital'srule, we get

$$
F(1)=\frac{D^{\prime}(1)}{D^{\prime}(1)+N^{t}(1)} \text {. }
$$




\section{SYSTEM QUEUE PERFORMANCE MEASURES}

Let $L_{q}$ a chance to demonstrate the reliable state typical number of customers in the line. By then

$$
L_{q}=\left.\frac{d}{d z} F(z)\right|_{z=1}=\left.\frac{d}{d z}\left\{\frac{N(Z)}{D(Z)}\right\}\right|_{z=1}
$$

Where $N(Z)$ and $D(Z)$ are the numerator and denominator of (36) .

Since $F(z)=\frac{0}{0}$ at $z^{=1}$, we utilize two fold separation and get

$$
\begin{aligned}
& L_{q}=\lim _{z \rightarrow 1} \frac{d}{d z} Y_{q}(z)=\frac{D^{\prime}(1) N^{\prime \prime}(1)-D^{\prime \prime}(1) N^{\prime}(1)}{2\left(D^{\prime}(1)\right)^{2}} \\
& N^{\prime}(1)=\lambda^{P}\left[E\left(J_{1}\right)+E\left(J_{2}\right)+E\left(J_{3}\right)\right]+E\left(J_{4}\right) \\
& N^{\prime \prime}(1)=\left(\lambda^{P}\right)^{2}\left[E\left(J_{1}^{2}\right)+2 E\left(J_{1}\right) E\left(J_{2}\right)+2 E\left(J_{1}\right) E\left(J_{3}\right)+\right. \\
& \left.2 E\left(J_{2}\right) E\left(J_{3}\right)+E\left(J_{2}^{2}\right)+E\left(J_{3}\right)\right]
\end{aligned}
$$

$$
\begin{aligned}
& D^{\prime}(1)=1-\lambda^{P} E\left(J_{1}\right)-\left(1-r E\left(J_{4}\right)\right) \lambda^{P}\left(E\left(J_{1}\right)+\right. \\
& \left.E\left(J_{2}\right)+E\left(J_{3}\right)\right)+r E\left(J_{4}\right)\left(-\lambda^{P}+\xi\right) \\
& D^{\prime \prime}(1)=-\left(\lambda^{P}\right)^{2} E\left(J_{1}^{2}\right)+r E\left(J_{4}\right) \lambda^{P}\left(-\lambda^{P}+\xi\right)\left(E\left(J_{1}\right)+\right. \\
& \left.E\left(J_{2}\right)+E\left(J_{3}\right)\right)-(1+r)\left(\lambda^{P}\right)^{2}\left[E\left(J_{1}^{2}\right)+2 E\left(J_{1}\right) E\left(J_{2}\right)+\right. \\
& \left.2 E\left(J_{1}\right) E\left(J_{3}\right)+2 E\left(J_{2}\right) E\left(J_{3}\right)+E\left(J_{2}^{2}\right)+E\left(J_{3}\right)\right]+ \\
& \left(E\left(J_{1}\right)+E\left(J_{2}\right)+E\left(J_{3}\right)\right)\left(-\lambda^{P}\right) r E\left(J_{4}\right)\left(-\lambda^{P}+\xi\right)- \\
& r E\left(J_{4}^{2}\right)(-\lambda+\xi)^{2}
\end{aligned}
$$

Substituting (40) - (44) in (40), we obtain $L_{q}$ and all the other measures using Little's formula

$$
W_{q}=\frac{L_{q}}{\lambda}, W=\frac{L}{\lambda}, L=L_{q}+\rho .
$$

\section{NUMERICAL JUSTIFICATION OF THE MODEL}

Assume that service time follows exponential dis Assume that service time follows exponential distribution in particular and based on this condition, the numerical justification is elaborated below:

The values are collected accordingly:

$E\left(J_{1}\right)=\frac{1}{\theta_{1}}, E\left(J_{2}\right)=\frac{1}{\theta_{2}}, E\left(J_{3}\right)=\frac{1}{\theta_{3}}, E\left(J_{4}\right)=\frac{1}{\theta_{4}}, E\left(J_{1}^{2}\right)=$ $\frac{2}{\theta_{1}^{2}}, E\left(J_{2}^{2}\right)=\frac{2}{\theta_{2}^{2}}, E\left(J_{3}^{2}\right)=\frac{2}{\theta_{3}^{2}}, E\left(J_{4}^{2}\right)=\frac{2}{\theta_{4}^{2}}, r=0.5, \xi=$ $1, \theta_{1}=1.5, \theta_{2}=2, \theta_{3}=2.5, \theta_{4}=3, \lambda^{P}=3.5$

Table I

Tabulated Values Regarding Variation of $\mathrm{r}=0.5,0.8,1,1.3,1.5$

\begin{tabular}{|l|l|l|l|l|l|}
\hline $\mathrm{Q}$ & $\rho$ & $L_{q}$ & $L$ & $W_{q}$ & $W$ \\
\hline 0.4698 & 0.5302 & 4.495 & 5.0252 & 1.2843 & 1.4358 \\
\hline 0.462 & 0.538 & 6.6339 & 7.1719 & 1.8954 & 2.0491 \\
\hline 0.4565 & 0.5435 & 8.2221 & 8.7656 & 2.3492 & 2.5045 \\
\hline 0.4485 & 0.5515 & 10.8835 & 11.435 & 3.1096 & 3.2671 \\
\hline 0.4339 & 0.5661 & 14.0351 & 14.6012 & 4.01 & 4.1718 \\
\hline
\end{tabular}

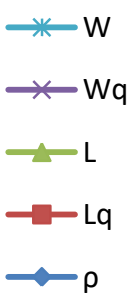

Fig. 1Variation of $\mathbf{r}$

Table II

Tabulated Values Regarding Variation Of $\xi=1,1.5,2,2.5,3$

\begin{tabular}{|l|l|l|l|l|l|}
\hline $\mathrm{Q}$ & $\rho$ & $L_{q}$ & $L$ & $W_{q}$ & $W$ \\
\hline 0.4698 & $\begin{array}{l}0.530 \\
2\end{array}$ & 4.495 & 5.0252 & 1.2843 & 1.4358 \\
\hline 0.4657 & $\begin{array}{l}0.534 \\
3\end{array}$ & 4.5776 & 5.1119 & 1.3079 & 1.4606 \\
\hline 0.4616 & $\begin{array}{l}0.538 \\
4\end{array}$ & 4.6701 & 5.2085 & 1.3343 & 1.4881 \\
\hline 0.4574 & $\begin{array}{l}0.542 \\
6\end{array}$ & 4.7733 & 5.3159 & 1.3638 & 1.5188 \\
\hline 0.4531 & $\begin{array}{l}0.546 \\
9\end{array}$ & 4.8876 & 5.4345 & 1.3964 & 1.5527 \\
\hline
\end{tabular}

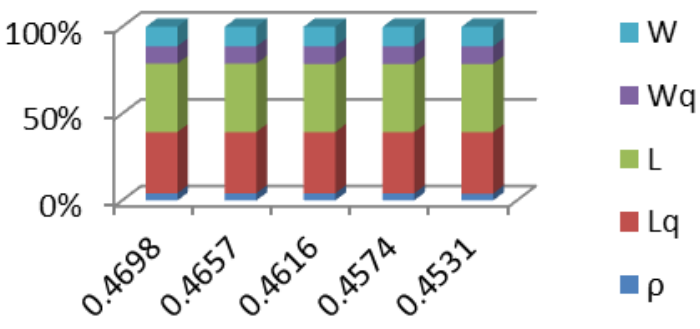

Fig. 2 Variation of $\xi$

\section{NUMERICAL DISCUSSION}

In Table 1, keeping the majority of the parameters dependable and developing the input favorable position parameter alone, it prompts an expansion in all the execution measures obviously. Like way in Table 2, the likelihood of association intrusion makes the structure to a little expansion in the execution measures. All the above outcomes are as expected. Graphical structures still stresses the model to a reasonable comprehension.

\section{CONCLUSION}

The model described above particularly cleared up the administration, stages of compulsory vacation and optional extended vacation in a non markovian covering model. Every one of these parameters has an effect over all the execution measures. The outcomes are not surprisingly. As a future work, a remain by server, feedback service, break down, reservice can be introduced in the midst of the period of discrete. Fix procedure can be given in stages. Furthermore balking can be presented.

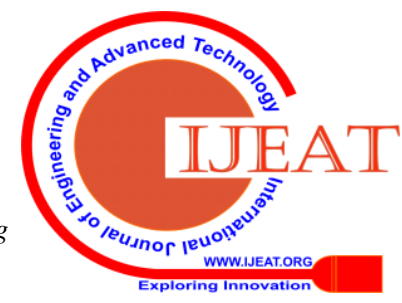




\section{Queuing Analysis on Multiple Vacation Policies and Reneging}

This showcase accept obvious employment in gathering units, correspondence structure, movement crossing focuses, and so forth.

\section{REFERENCES}

1. A. Aissani and J.R. Artalejo, "On the single server retrial queue subject to breakdowns", QueueingSystems,Vol.30, No.3, pp.309-321, 1988.

2. B. Balamurugan and S. Maragathasundari, "A study on the performance analysis of a batch arrival queue with two stages of service Bernoulli schedule vacation extended vacation and service interruption", International journal of computer applications,Vol.124, No.12, pp.3337,2015.

3. A. Borthakur and G. Choudhury, "On a batch arrival Poisson queue with generalized vacation, SankhyaSer.B, Vol.59, No.3, pp.369383, 1997.

4. Dhanalakshmi and S. Maragathasundari ,"Mobile adhoc networks problem- A queuing approach", International journal of communication networks and distributed systems,vol.21,No.4,2018.

5. R.F. Khalaf, K. C. Madan and C.A. Lucas., "An M[x]/G/1 Queue with Bernoulli schedule, General vacation times, random breakdowns, general and general repair times", Applied mathematical sciences, Vol.5, No.1, pp.35-51, 2011

6. K. Karthikeyan and S. Maragathasundari, "Batch arrival of two stages with standby server during general vacation time \& general repair time", International Journal of Mathematical archive, Vol.6, No.4, pp.43-48, 2015.

7. K. Kavitha and S. Maragathasundari, "Analysis of Non Markovian queue with restricted admissibility and optional types of repair", International journal of scientific research and management studies, Vol.2, No.5, pp.244-252, 2012.

8. K.C. Madan. and A.Z. Abu-Dayyeh, "On a single server queue with optional phase type server vacations based on exhaustive deterministic service and a single vacation policy", Applied Mathematics and Computation, Vol.149,No.3, pp. 723-734,2004.

9. K.C. Madan and G. Chodhury, "An M[x]/G/1 queue with Bernoulli vacation schedule under restricted admissibility policy”,Sankhaya,Vol.66, pp.172-193,2004.

10. S. Maragathasundari, "A bulk arrival queuing model of three stages of service with different vacation policies, service interruption and delay time", American International Journal of Research in Science, Technology, Engineering\& Mathematics, Vol.11,No.1,pp.5256,2015.

11. S. Maragathasundari and S. Srinivasan, "Analysis of M/G/1 feedback queue with three stages and multiple server vacation", Applied mathematical sciences, Vol.6, No.125, pp.6221-6240, 2012.

12. S. Maragathasundari and K. Karthikeyan, "A bulk queuing model of optional second phase service with short and long vacations", International Journal of scientific research in science and technology, Vol.2, No.5, pp.196-201,2016.

13. R.F. Khalaf, K.C. Madan and C.A. Lukas , "An $M x / \mathrm{G} / 1$ with Bernoulli schedule general vacation times, general extended vacations, random breakdown, general delay time for repairs to start and general repair times", Journal of Mathematical Research, Vol.3, No.4, 2011, pp.820.

14. S. Sowmiah and S. Maragathasundari, "A study on the analysis of performance measure of bulk input queue with $\mathrm{N}$ type of additional optional service, service interruption and deterministic vacation", Imperial Journal of Interdisciplinary Research, Vol.2, No.8, pp. 14361444,2016

\section{AUTHORS PROFILE}

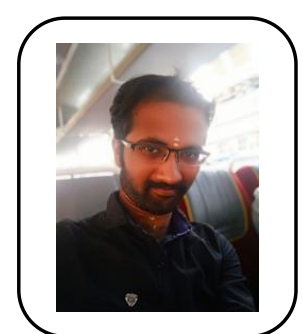

Mr. P. Suthersan pursued his B.Sc degree from Thiagarajar College, Madurai in 2013. He got his M.Sc degree from Thiagarajar College, Madurai in 2015. He obtained his M.Phil degree from Thiagarajar College, Madurai in 2016. He had 3 years of teaching experience. Now he is doing research area in Queuing Theory in Kalasalingam Academy of Research and Education, Anand Nagar, Krishnankoil-626126, Tamilnadu, India.

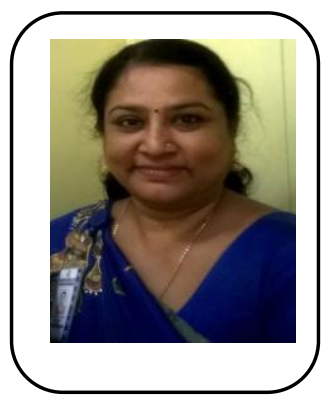

Dr. S. Maragatha Sundari acquired her B.Ed. degree from V.O.C Teachers College, Tuticorin in 1993. She got her M.Sc. in Mathematics from Manonmaniam Sundaranar University; Tirunelveli in 1995 and her M.Phil. degree from Madurai Kamaraj University, Madurai in 2003. She did her Ph.D. in Sathyabama University, Chennai, India. She has more than 17 years of instructing knowledge. She has distributed more than 50 inquire about papers in national and international journals. She has displayed and distributed papers at national and international conferences. She is right now filling in as an Associate Professor in the Department of Mathematics in Kalasalingam Academy of Research And Education, Anand Nagar, Tamilnadu, Krishnankovil-626126, India. In addition, she is doing her research guidance for five research scholars. 